\title{
Carbon Monoxide Diffusing Capacity Decreased, CTCAE
}

National Cancer Institute

\section{Source}

National Cancer Institute. Carbon Monoxide Diffusing Capacity Decreased, CT CAE. NCI Thesaurus. Code C143350.

A finding based on lung function test results that indicate a decrease in the lung capacity to absorb carbon monoxide. 